\section{POS0104 ESSDAI AND ITS ASSOCIATION WITH PATIENT OUTCOMES IN SJÖGREN'S SYNDROME: A REAL- WORLD SURVEY IN THE US}

B. Ndife ${ }^{1}$, B. Hoskin ${ }^{2}$, N. Booth ${ }^{2} .{ }^{1}$ Novartis Pharmaceuticals Corp., Novartis, East Hanover, United States of America; ${ }^{2}$ Adelphi Real World, Adelphi Real World, Bollington, United Kingdom

Background: The EULAR Sjögren's syndrome disease activity index (ESSDAI) is considered the gold standard for measuring Sjögren's syndrome disease activity in clinical trials, but there is limited evidence of its application in the real-world.

Objectives: To describe the distribution of ESSDAI scores in the real-world and it's association with patient outcomes.

Methods: Data were drawn from the Adelphi Primary Sjögren's syndrome (pSS) Disease Specific Programme ${ }^{\mathrm{TM}}$, a real-world point-in-time survey of rheumatologists and their consulting pSS patients in the United States. Proxy ESSDAI scores were calculated for each patient by assigning a score to the rheumatologists' perception of "not present," "mild", "moderate" or "severe" for each of the twelve domains of the ESSDAI. ESSDAI scores were then grouped according to the definitions of mild (ESSDAI 0-4), moderate (ESSDAI 5-13) and severe (ESSDAI $\geq 14$ ). Rheumatologists provided data about patient demographics and clinical characteristics. Patients self-completed patient reported outcome (PRO) tools including the EuroQol 5-dimension 5-level utility score (EQ-5D), Work Productivity and Activity Impairment questionnaire (WPAI) and The Functional Assessment of Chronic Illness Therapy - Fatigue (FACIT-F). Differences in clinical characteristics and patient-reported outcomes were examined according to ESSDAI severity score. Spearman's Rho association was used to assess the correlation of ESSDAI severity with PROs.

Results: Rheumatologists ( $n=84$ ) provided data for 511 pSS patients, mean age 53.3 years, $88.5 \%$ female, $79.8 \%$ white/Caucasian and mean time since diagnoses 4.6 years. Of the 511 patients, $44.2 \%$ were considered to be mild, $30.9 \%$ moderate and $24.9 \%$ severe in terms of their calculated ESSDAI score. Demographic characteristics of the three ESSDAI groups were similar, Table 1. Patients with severe ESSDAI scores have been diagnosed with pSS for longer than those with mild or moderate ESSDAI scores.

Increasing ESSDAI severity was associated with worse EQ-5D utility scores (rho=-0.346, p<0.0001), worse FACIT-F scores (rho $=-0.277, p<0.0001)$ and worse overall work impairment ( $r h o=0.462, p<0.0001)$.

Table 1. Demographic characteristics of pSS patients in the US, by ESSDAI severity

\begin{tabular}{|c|c|c|c|c|}
\hline & $\begin{array}{l}\text { Total } \\
(\mathrm{n}=511)\end{array}$ & $\begin{array}{l}\text { Mild ESSDAI } \\
\quad(n=226)\end{array}$ & $\begin{array}{l}\text { Moderate } \\
\text { ESSDAI } \\
(\mathrm{n}=158)\end{array}$ & $\begin{array}{l}\text { Severe } \\
\text { ESSDAI } \\
(n=127)\end{array}$ \\
\hline Patient age, mean (SD) years & $53.3(14.2)$ & $52.6(15.0)$ & $53.6(14.0)$ & $54.2(12.9)$ \\
\hline $\begin{array}{l}\%(n) \text { female } \\
\text { Ethnicity, \% (n) }\end{array}$ & $88.5(452)$ & $89.4(226)$ & $88.6(158)$ & $86.6(127)$ \\
\hline White/Caucasian & $79.8(408)$ & $86.3(195)$ & 74.7 (118) & $74.8(95)$ \\
\hline African-American & $9.2(47)$ & $6.2(14)$ & $10.1(16)$ & $13.4(17)$ \\
\hline Hispanic/Latino & $6.1(31)$ & $5.3(12)$ & $8.2(13)$ & $4.7(6)$ \\
\hline Other & $4.9(25)$ & $2.2(5)$ & $7.0(11)$ & $7.1(9)$ \\
\hline $\begin{array}{l}\text { Time since diagnosis, mean (SD) } \\
\text { years [n] } \\
\text { Insurance type, \% (n) }\end{array}$ & $4.6(5.4)$ [379] & $4.0(4.9)[162]$ & 4.9 (5.6) [118] & $5.1(5.8)[99]$ \\
\hline $\begin{array}{l}\text { Commercial (including employer } \\
\text { provided) }\end{array}$ & $59.9(306)$ & $62.4(141)$ & $56.3(89)$ & $59.8(76)$ \\
\hline Medicare & $20.5(105)$ & $18.1(41)$ & $23.4(37)$ & $21.3(27)$ \\
\hline Health insurance exchange plan & $9.6(49)$ & $10.2(23)$ & $10.1(16)$ & $7.9(10)$ \\
\hline Other & $9.6(49)$ & $8.8(20)$ & $9.5(15)$ & $11.0(14)$ \\
\hline $\begin{array}{l}\text { None } \\
\text { Employment status, \% (n) }\end{array}$ & - (2) & $-(1)$ & - (1) & $-(0)$ \\
\hline Working full or part time & $58.9(301)$ & $61.9(140)$ & $53.2(84)$ & $60.6(77)$ \\
\hline $\begin{array}{l}\text { Long-term sick/unemployed/ } \\
\text { retired }\end{array}$ & 24.5 (125) & $20.8(47)$ & $27.2(43)$ & $27.6(35)$ \\
\hline Homemaker & $12.7(65)$ & $10.2(23)$ & $17.1(27)$ & $11.8(15)$ \\
\hline Other/unknown & $3.9(20)$ & $7.1(16)$ & $2.5(4)$ & $-(0)$ \\
\hline $\begin{array}{l}\text { Smoking status, \% (n) current } \\
\text { smoker }\end{array}$ & $6.8(35)$ & $3.5(8)$ & $5.7(9)$ & $14.2(18)$ \\
\hline
\end{tabular}

Conclusion: A worsening severity on the ESSDAI scale is associated with worse outcomes for patients in the real-world. Treating systemic disease beyond symptomatic treatments is important to improve patient outcomes.

Disclosure of Interests: Briana Ndife Shareholder of: Novartis Pharmaceuticals Corp, Employee of: Novartis Pharmaceuticals Corp, Ben Hoskin: None declared, Nicola Booth: None declared

DOI: 10.1136/annrheumdis-2021-eular.3807

\section{POS0105 \\ PREDICTORS OF FLARE IN SLE PATIENTS ATTAINING LUPUS LOW DISEASE ACTIVITY STATE: A REAL-LIFE COHORT STUDY OF 292 PATIENTS WITH 36-MONTH FOLLOW-UP}

A. R. Cunha ${ }^{1}$, L. Saraiva ${ }^{2}$, J. A. P. Da Silva ${ }^{2,3}$, L. Inês ${ }^{4,5} \cdot{ }^{1}$ Centro Hospitalar do Baixo Vouga, Rheumatology, Aveiro, Portugal; ${ }^{2}$ Centro Hospitalar e Universitário de Coimbra, Rheumatology, Coimbra, Portugal; ${ }^{3}$ Coimbra Institute for Clinical and Biomedical Research(i.CIBR), Faculty of Medicine, Coimbra, Portugal; ${ }^{2}$ Centro Hospitalar e Universitário de Coimbra, Rheumatology, Coimbra, Portugal; ${ }^{5}$ University of Beira Interior, Faculty of Health Sciences, Covilhã, Portugal

Background: Lupus Low Disease Activity State (LLDAS) is a target for management of patients with SLE, that should be maintained in the long-term by preventing flares. Stratification of flare risk would be useful to optimize management. Objectives: To identify predictors of flare in SLE patients attaining LLDAS. Methods: Patients with SLE fulfilling classification criteria [ACR (1997) and/or SLICC and/or EULAR/ACR], followed at an academic lupus clinic from January 2017 to March 2020 were eligible. Baseline for each patient was the first visit with LLDAS within the study period. Patients never fulfilling LLDAS were excluded. Flares were identified as change from baseline by 3 instruments: revised SELENA flare index (r-SFI); SLEDAI-2K; Systemic Lupus Erythematosus Disease Activity Score (SLE-DAS). Time to first flare up to 36 months was identified separately for each instrument. Predictors of flare were sought through survival analysis, with distinct models for each of the three definitions of flare. Univariate analysis was performed using Kaplan-Meir curves and Log-Rank tests. Tested variables at baseline were: gender; age at time of SLE diagnosis; disease duration; cumulative SLE organ involvement (arthritis; mucocutaneous; renal; neurologic; haematological; anti-phospholipid syndrome); cumulative immunological features (anti-dsDNA; anti-Sm; anti-RNP, anti-phospholipid antibodies; hypocomplementemia); ongoing treatment (hydroxychloroquine; prednisone; immunosuppressants). Variables with $\mathrm{p}<0.1$ were further tested in multivariate Cox regression models. Hazard ratios (HR) were determined with $95 \%$ confidence intervals $(95 \% \mathrm{Cl})$.

Results: From 322 patients in this SLE cohort, 292 (90.7\%) fulfilled LLDAS and were included in the analyses (female: $87.3 \%$; mean age: $46.2 \pm 14.5$ years; previous lupus nephritis: $36.0 \%$; receiving ongoing antimalarials, immunosuppressants, glucocorticoids: $92.8 \%, 34.6 \%$ and $29.8 \%$, respectively. Over follow-up the proportion of patients with flares according to each definition were: $28.4 \%$ (r-SFI), 24.7\% (SLE-DAS) and 13.4\% (SLEDAI-2K). The r-SFI flares were moderate in $28.9 \%$ and severe in $9.6 \%$ of the cases. From all patients, $54.1 \%$ maintained stable glucocorticoid-free control of the disease, without flares during follow-up. In the multivariate models, the following parameters were independent predictors of flare, as defined by any of the definitions (Table 1): anti-RNP+; oral glucocorticoids; immunosuppressants.

Conclusion: Patients attaining LLDAS but requiring ongoing treatment with immunosuppressants and/or glucocorticoids present a higher risk of flare and thus might need a tighter clinical monitoring. Anti-RNP+ was newly identified as a potential biomarker for higher risk of flares. Glucocorticoid-free, stable low disease activity is an achievable target.

\section{REFERENCES:}

[1] Mathian A, Pha M, Haroche J, Cohen-Aubart F, Hié M, Pineton de Chambrun $M$, et al. Withdrawal of low-dose prednisone in SLE patients with a clinically quiescent disease for more than 1 year: a randomised clinical trial. Ann Rheum Dis. 2020;79(3):339-46.

[2] Inês L, Duarte C, Silva RS, Teixeira AS, Fonseca FP, da Silva JA. Identification of clinical predictors of flare in systemic lupus erythematosus patients: a 24-month prospective cohort study. Rheumatology (Oxford). 2014;53(1):85-9.

Table 1. Predictors of flare in multivariate Cox regression according to each of the flare definitions (r-SFI; SLE-DAS; SLEDAI-2K)

\begin{tabular}{|c|c|c|c|}
\hline & r-SFI & SLE-DAS & SLEDAI-2K \\
\hline Anti-RNP+ & $2.11(1.30-3.42)$ & $2.39(1.44-3.95)$ & $2.22(1.11-4.42)$ \\
\hline Immunosuppressants & $1.96(1.22-3.15)$ & $2.32(1.38-3.88)$ & $2.26(1.12-4.54)$ \\
\hline Prednisone* ${ }^{*}$ & $1.93(1.19-3.14)$ & $1.99(1.18-3.35)$ & $2.17(1.07-4.38)$ \\
\hline Blood cytopenias ${ }^{\S}$ & $2.08(1.03-4.17)$ & n.s. & n.s. \\
\hline Arthritis $\$$ & n.s. & n.s. & $2.23(1.12-4.44)$ \\
\hline
\end{tabular}

* Prednisone $\leq 7.5 \mathrm{mg} /$ day as required by LLDAS. ${ }^{\S}$ Blood cytopenias; arthritis: cumulative SLE features up to baseline. Risk for each predictor reported as Hazard Ratio ( $95 \%$ Confidence Interval); n.s.: non-significant

Disclosure of Interests: None declared DOI: 10.1136/annrheumdis-2021-eular.478 